\title{
Dossiê \\ Estudos de Gênero e Museologia
}

\author{
Mariana Moraes de Oliveira Sombrio ' \\ Marijara Souza Queiroz ${ }^{2}$
}

\begin{abstract}
A origem das coleções e dos museus brasileiros nos conduz a acervos museológicos compostos por artefatos históricos, artísticos, arqueológicos e objetos das mais diversas naturezas que servem, em primeira instância, à construção de uma narrativa hegemônica que ressalta a memória dos vencedores, dos dominadores ou dos heróis. Ou seja, do homem e do universo masculino. O resultado dessa composição tem favorecido a reiteração da visão androcêntrica e a permanência de dispositivos de distinção de classes, gênero e raça para fins de controle social e consolidação de hegemonias. Como parte do mecanismo museológico, o filtro da memória que seleciona o que é musealizado geralmente é manipulado a favor da manutenção de relações de poderes secularmente instituídas na sociedade.
\end{abstract}

A história do feminismo no Brasil remete ao século XIX e perpassa fatos e questões históricas que compõem as grandes narrativas nacionais. Tomemos como exemplo a Constituição de I89| que não excluía a mulher do direito ao voto simplesmente por não reconhecê-la como sujeito dotado de direitos, o que abriu precedentes para que as mulheres reivindicassem o direito de eleger suas representantes. Margens de manobras como esta, historicamente bem aproveitadas pelas mulheres, têm sido negligenciadas nas narrativas museais e nos estudos sobre gênero no campo da museologia.

De todo modo, mudanças significativas têm ocorrido pautando este debate, seja através de atividades pontuais, isoladas ou engajadas, mas quase sempre advindas de iniciativas de pesquisadores, ativistas ou técnicos que atuam no campo museal. Pessoas que têm se comprometido individualmente com a construção de narrativas socialmente inclusivas em contraponto à reprodução do tradicional discurso patriarcal dado como universal. Da mesma forma, nota-se um crescimento recente de estudos sistemáticos ou regulares sobre gênero e museologia no país.

Nesse sentido, o Dossiê Estudos de Gênero e Museologia buscou reunir produções que relacionam os estudos de gênero com o campo dos museus e da museologia, em diferentes perspectivas, de modo a pautar esse debate. Interessa-nos ainda explicitar as diversas possibilidades de se (re)pensar os museus em seus processos e práticas, as transformações no campo disciplinar da museologia influenciadas por teorias feministas, e a extensão com que as análises de gênero têm proporcionado novos objetos de estudo, novos pontos de vista e novas interpretações sobre acervos e coleções musealizadas em diferentes instituições do país.

No conjunto de textos apresentados aqui identificamos algumas linhas temáticas principais que, de modo geral, abrangem estudos voltados a história dos museus, da museologia e das coleções no Brasil, explicitando a participação das mulheres nesses espaços e atividades; que enfatizaram as contribuições dos estudos e teorias feministas no campo museológico; e que articularam mais profundamente as problemáticas de gênero com questões sobre raça e sexualidade em espaços museais. Essas temáticas gerais orientaram a ordem de apresentação dos artigos e caracterizam algumas tendências recentes na articulação de objetos de estudo da museologia com os estudos de gênero e diversidade.

Em relação a história dos museus e das coleções no Brasil, a necessidade ainda premente de observar as relações de gênero nos estudos sobre colecionismo foi o tema abordado por Ana Cristina Audebert em seu artigo que explora questões sobre a visibilidade das contribuições das mulheres nas memórias preserva-

I Pesquisadora de pós-doutorado (bolsista FAPESP, processo 2016/22452-9) no Programa de Pós-Graduação Interunidades em Museologia da USP.E-mail: marisombrio@gmail.com

2 Professora Assistente do Curso de Museologia da Universidade de Brasília. E-mail: marijara@unb.br 
das e comunicadas por instituições museológicas. A autora nos lembra que tanto os objetos colaboram para instituir ou reproduzir papéis de gênero quanto o próprio gênero institui papéis a serem desempenhados pelos objetos e coleções. Os museus escolhem representar os gêneros de determinadas formas e é aí que a análise feminista tem disputado espaços e reivindicado representações mais críticas e igualitárias. Há ainda uma ausência de pesquisas associadas às mulheres colecionadoras e é preciso questionar as formas como a memória é construída tanto pelos objetos presentes quanto pelos que estão ausentes nos museus.

Explicitando e questionando características da presença de mulheres em exposições históricas, Ana Paula Simioni e Carlos Lima Junior analisaram um conjunto de três telas concebidas para as comemorações do centenário da Independência, em 1922, com representações de figuras femininas retratadas como protagonistas da história nacional. Os retratos em questão são os de Maria Quitéria e Leopoldina de Habsburgo, pertencentes ao acervo do Museu Paulista, e a tela Sessão do Conselho do Estado, elaborada por Georgina de Albuquerque, hoje presente no Museu Histórico Nacional (RJ). $O$ texto evidencia a profundidade com que essas imagens constituíram discursos sobre a história profundamente perpassados pelas dimensões de gênero.

Alguns artigos presentes neste dossiê trazem contribuições significativas sobre trajetórias de mulheres, artistas, cientistas, colecionadoras, explicitando essas atuações e problematizando a invisibilidade a que foram submetidas ou os espaços de memória a que foram relegadas. $\mathrm{O}$ artigo de Clovis Britto e Paulo Prado, por exemplo, discorre sobre espaços ocupados por mulheres e o papel do luto e da viuvez na sociedade goiana a partir de memórias de Cora Coralina e de sua mãe, Jacintha Luiza, analisando em especial coleções de fotografias preservadas por elas, hoje guardadas em sua casa musealizada, o Museu Casa de Cora Coralina. Ao narrar aspectos dessa história, os autores problematizam a função atribuída pela sociedade burguesa às mulheres como guardiãs de memórias e do luto, responsáveis pela guarda de fotografias, objetos, roupas e outros meios de recordação no ambiente doméstico, processo marcado pela saudade, superação do luto e por marcas de gênero.

A guarda da memória como requisito feminino converte-se em brechas para a representação social da mulher a partir dos Museus Casas no texto apresentado por Marijara Souza Queiroz e Jéssica Venancio Freitas que discorrem sobre a experiência social dos trajes de alta costura de Eufrásia Teixeira Leite, assinados pelo estilista Charles Worth. Como parte do acervo do Museu Casa da Hera, os trajes evidenciam marcadores sociais que estabelecem o universo reservado às mulheres da aristocracia cafeeira na segunda metade do século $\mathrm{XIX}$ e início do $\mathrm{XX}$, mas também revelam estratégias utilizadas por mulheres para driblar as barreiras sociais erguidas, os lugares reservados e os papéis predefinidos como formas de opressão feminina.

As especificidades da trajetória de Eufrásia Teixeira Leite também pautam as reflexões de Eneida Quadros Queiroz, que acrescenta ao elenco de escolhas pró-emancipatórias dessa personagem uma história de amor vivida com o abolicionista Joaquim Nabuco na qual dispensou matrimônio ou convenções sociais que a submetesse ao papel secundário de esposa. Tendo como base romances sobre mulheres que se desenvolvem no cenário dos museus - A Mulher e a Casa e Úmida Trama -, de autoria própria, Queiroz destaca em seu artigo o projeto literário Histórias Poéticas dos Museus, que busca engajar o público por meio da biografia de mulheres e da literatura associada aos museus e a seus acervos.

Trajetórias profissionais de pesquisadoras que atuaram no campo da etnologia em museus brasileiros, na primeira metade do século XX, são analisadas por Mariana Sombrio. As personagens abordadas neste artigo estabeleceram conexões com diferentes museus como o Museu Paulista, o Museu Nacional do Rio de Janeiro e o Museu Paranaense, adentrando esses espaços. Abrigadas por essas instituições elas produziram estudos, reuniram coleções, desenvolveram teorias e um olhar atento a essas experiências que podem nos ajudar a compreender melhor as formas de participação de diferentes mulheres em disciplinas e práticas científicas e a própria história das ciências no país.

Também no contexto da história das ciências, Maria de Fátima Medeiros de Souza trata da relevante contribuição das mulheres viajantes na documentação científica do século XIX a partir da análise de uma das ilustrações que acompanham o diário de viagem da inglesa Maria Graham ao Brasil:A Dragon Tree, da Ilha de Tenerife, árvore milenar conhecida pelos seus potenciais medicinais. Explora a influência de Alexander von Humboldt e de outros naturalistas como padrão estético nas obras escritas e imagéticas das viajantes, caracterizadas pela conjugação das perspectivas científicas e artísticas. 
Allice Lopes e Ana Lúcia Gomes demonstram que as primeiras políticas voltadas para os museus brasileiros foram estabelecidas a partir de aspirações culturais de um Estado caracteristicamente masculino e o impacto das restrições aplicadas às mulheres no passado reverbera até hoje no campo do patrimônio.A partir dessa contextualização histórica, as autoras fazem uma discussão sobre os direitos culturais e as mulheres baseando-se na análise de legislações relativas ao patrimônio cultural no Brasil aprovadas entre os anos de 1957 a 2017, enfatizando a questão da maternidade no espaço dos museus e a necessidade de ampliação do acesso de mulheres mães aos espaços de patrimônio.

Algumas autoras deram ênfase à análise de perspectivas teóricas dos estudos feministas e às formas como esses estudos vêm sendo articulados com problemáticas específicas dos estudos sobre museus. Judite Primo e Vânia Brayner reafirmam a ebulição dos movimentos sociais feministas contemporâneos que têm contribuído para visibilizar as diversas questões ao tempo que apontam para a necessidade da adoção de políticas de memória do feminino nas lutas sociais e na resistência política de modo a pôr fim aos silenciamentos históricos aos quais as mulheres foram submetidas.

A partir de uma revisão de conceitos museológicos e sobre a historiografia do feminismo, Camila Wichers explicita relações constituídas entre o pensamento feminista e a museologia, relacionando o início desses estudos aos movimentos conhecidos como Nova Museologia, Sociomuseologia e Museologia Social, bem como práticas comunitárias em memórias e museus, contexto que tem possibilitado um diálogo mais frutífero entre o campo da museologia e os diversos feminismos. A autora chama a atenção para o fato das memórias marcadas por gênero, classe ou raça terem sido constantemente destinadas à subalternidade e a potencialidade das representações coletivas em estimular processos de inclusão ou exclusão social. Destaca ainda o importante papel do feminismo interseccional para se pensar os processos de musealização e de memória, que vai de encontro a um conjunto mais diversificado de mulheres presente hoje no campo da museologia que, com trajetórias de luta e superação, tem deixado impresso em seus trabalhos esse lugar de fala.

Na demarcação do seu lugar de fala, Luzia Gomes Ferreira expõe suas “memórias atlânticas no exercício da poética intermediada pela teoria acadêmica" fazendo uso das epistemologias de gênero, com narrativa em primeira pessoa, e do próprio corpo de mulher negra como experimento artístico visual. De acordo com os conceitos de autoavaliação e autodefinição de Patrícia Hill Collins, que possibilitam a construção de um pensamento crítico e científico sobre o feminismo de mulheres negras, Ferreira apresenta sua trajetória pessoal para falar de uma realidade mais ampla sobre a condição de ser mulher e habitar uma pele negra. Para além da criação de museus para negros e negras, questiona a necessidade de produção de conhecimento no campo museológico voltado para as questões de gênero e raça.

No ínterim dos museus, Girlene Chagas Bulhões fala da invisibilidade, do silenciamento e da marginalização da memória de mulheres, em especial de mulheres negras, nas instituições museais. A proposição reflexiva sobre palavras "ditas" e não-ditas" poeticamente usadas como analogia para falar dos museus e de "performances museais" excludentes ou marginalizadoras. A narrativa rizomática que nos apresenta Bulhões conduz a exemplos de ações contra hegemônicas desenvolvidas, em especial, no Museu das Bandeiras (Goiás, GO). Desenvolve a ideia de "museologia do afeto", que pode ser caracterizada por uma museologia mais ajustada com as demandas humanas e sociais. Neste caso, em se tratando da nossa sociedade patriarcal, por uma museologia socialmente mais engajada com as questões de gênero raça e classe.

A ausência ou marginalização de mulheres negras nas narrativas museais foi evidenciada também na análise de Renata Bittencourt que faz um deslocamento contextual entre o nu feminino na história da arte - com alta representatividade nas coleções museológicas - à produção ativista de artistas feministas afroamericanas na década de 1970, que questiona a ausência de artistas mulheres nas exposições e nos museus. Apresenta dados relacionados ao acervamento de obras de artistas mulheres nos museus de arte considerando as variantes de sexo e raça, a partir dos quais é possível constatar a quase ausência ou presença silenciada de obras de mulheres negras. Para além de obras, preserva-se assim as estruturas racistas e sexistas da sociedade restando pequena margem de desvio para a subversão dessa ordem social. Dessa forma, omite-se e reduz-se a participação dessas mulheres na produção artística, já que são excluídas de mecanismos de representação social que instituem poderes, ideias e tradições como realidades estabelecidas.

De acordo com Jean Baptista e Tony Boita, com apoio de agentes e de instituições de cultura, o pró- 
prio Estado se encarrega de manter os dispositivos que garantem a sucessão de poderes e hierarquias já instituídas na sociedade. Nesse sentido, os autores partem de um levantamento sobre as ações museais voltadas para a memória LGBT no Brasil para questionar a indiferença dos museus e da museologia para as pessoas LGBT, o que está marcado na formação e gestão dos acervos (como possibilidade de representação social e preservação da memória a partir dos artefatos), como também no desenvolvimento de programas e políticas de Estado que incluam a questão LGBT na pauta das instituições museais. Com isso, clama por uma "Primavera LGBT", ação política de difusão e fomento dos museus brasileiros do Instituto Brasileiro de Museus, como possibilidade de incluir essa temática nacionalmente no campo dos museus e da museologia.

Este Dossiê percorre questões de diversidade, identidade, patrimônios, produção de conhecimento científico e memória social no campo museológico através de coleções, trajetórias, casos empíricos e reflexões teóricas que representam, narram ou conceituam os estudos de gênero nesta área. No conjunto, os textos aqui apresentados pautam o debate sobre gênero e interseccionalidades no campo da museologia.

Aproveitamos para agradecer a gentileza das Editoras desta Revista, as Professoras Ana Lucia de Abreu Gomes e Maria Margarete Lopes, que nos convidaram para organizar o Dossiê Estudos de Gênero e Museologia ao qual tomamos como presente, oferenda ou o Axé que se passa de geração a geração de mulheres. Agradecemos também às autoras e autores que gentilmente aceitaram nosso convite para apresentar suas experiências, seus estudos e pensamentos acerca do tema, o que resultou em um panorama ricamente diverso de possibilidades de pensar gênero e museologia. Esperamos que esse tema possa se desdobrar em possibilidades de se (re)pensar o fazer museológico e o museu a partir de um olhar mais crítico sobre a sociedade patriarcal. 